\title{
An Extension of the Universal Force Field for Metal-Organic Frameworks
}

\author{
Damien E. Coupry, ${ }^{\dagger}$ Matthew A. Addicoat, ${ }^{*} \ddagger$ and Thomas Heine ${ }^{\ddagger}$ \\ $\dagger$ Software for Chemistry and Materials, Vrije Universiteit, Theoretical Chemistry, De \\ Boelelaan 1083, 1081 HV Amsterdam, The Netherlands \\ $\ddagger$ Wilhelm-Ostwald-Institut für Physikalische und Theoretische Chemie, Fakultät für Chemie \\ und Mineralogie, Universität Leipzig, Linnéstr. 2, 04103 Leipzig, Germany \\ E-mail: matthew.addicoat@uni-leipzig.de
}

\begin{abstract}
We have extended the Universal Force Field for Metal-Organic Frameworks (UFF4MOF) to cover all moieties present in the most extensive framework library to date, i.e. the Computation-Ready Experimental (CoRE) database (Chem. Mater. 26, 6185 (2014)). Thus, we have extended the parameters to include the fourth and fifth row transition metals, lanthanides and an additional atom type for Sulphur, while the parameters of original UFF and of UFF4MOF are not modified. Employing the new parameters significantly enlarges the number of structures that may be subjected to a UFF calculation, i.e. more than doubling accessible MOFs of the CoRE structures and thus reaching over $99 \%$ of CoRE structure coverage. In turn, $95 \%$ of optimized cell parameters are within $10 \%$ of their experimental values. We contend these parameters will be most useful for the generation and rapid prototyping of hypothetical MOF structures from SBU databases.
\end{abstract}




\section{Introduction}

Metal-Organic Frameworks (MOFs) are a class of inorganic-organic crystalline materials, formed by combination of a metal or metal oxide cluster ('connector') with an organic 'linker' molecule. Since the publication of the now famous MOF-5 in 1999, ${ }^{1}$ over twenty thousand different MOFs have been synthesised and applied to tasks ranging from gas storage and separation, ${ }^{2-4}$ where the high surface area and pore volume is important; optical and chemical sensing ${ }^{5,6}$ in which the geometric arrangement of the linkers and electron transport within the framework are important; drug delivery and catalysis, ${ }^{7-10}$ where pore geometry and specific chemical interaction with the framework are important properties. Emphasising the increasing prominence of MOFs in materials chemistry, the Computation-Ready Experimental (CoRE) database ${ }^{11}$ of MOF structures was recently compiled from crystal structures archived in the Cambridge Structural Database (CSD). ${ }^{12}$ CoRE is a database of over 5000 high-quality reference structures for computational screening and development and is thus an excellent means to parameterize and validate a general force field for molecular framework materials.

The effectively infinite number of possible frameworks combined with the varied applications mean that computational investigation of these systems is vitally important, yet the periodic nature, and often large unit cells of MOFs, precludes the routine use of well-known computational methods such as Density Functional Theory (DFT). In particular, the desire to computationally screen vast numbers of plausible framework structures necessitates the use of highly efficient computational methods. Several groups have employed a variety of approaches in developing force fields for MOFs. ${ }^{13-15}$ A number of force fields have been developed to accurately describe individual important MOFs. One of the first such was the extended MM3 ${ }^{16}$ force field for MOF- $5^{17}$ and for later Copper paddlewheel -based MOFs, ${ }^{18}$ both from Schmid and coworkers. Recently, Smit and coworkers derived a force field from entirely periodic calculations to predict the $\mathrm{CO}_{2}$ and $\mathrm{H}_{2} \mathrm{O}$ adsorption isotherms in Mg-MOF- 
74 and Zn-MOF-74. ${ }^{19}$ Force fields have also been developed for In-soc-MOF ${ }^{20}$ rht-MOF- $1^{21}$ and ZIF-11 22

Many MOFs possess significant structural flexibility, and in these cases, this flexibility largely dictates the behaviour of the MOF w.r.t gas adsorption, thermal expansion and response to pressure. Grosch and Paesani developed a force field to describe the Zinc paddlewheel based DMOF-1 by using a genetic algorithm to fit the bonded force field terms to ab initio calculations of model building blocks. ${ }^{23}$ They were subsequently able to describe the breathing behaviour that occurs with different loadings of both benzene and isopropyl alcohol. Another force field that accurately captures breathing motion was derived for MIL53 from a set of both periodic and nonperiodic DFT calculations. ${ }^{24}$ Gascon also derived a force field to investigate gas adsorption and diffusion in MIL-53. ${ }^{25}$

Moving toward more general approaches, and more transferable force fields, Schmid and coworkers developed a genetic algorithm in order to systematically derive force field parameters in their MOF-FF. ${ }^{26,27}$ Bristow, Tiana and Walsh parameterised the BTW-FF force field from a training set containing representatives of three highly important isoreticular series, namely, the IRMOF- $n$, UiO- $n$ and HKUST MOFs. ${ }^{28}$ Probably the most general approach so far, recently, Vanduyfhuys et. al published a program, QuickFF, ${ }^{29}$ that automates the process of force field generation beginning from quantum mechanical calculations. In the case of MOFs, by employing DFT calculations on both connector- and linker- centred clusters, QuickFF was validated against previously derived force fields for MIL-53(Al) ${ }^{24}$ and MOF- $5^{17}$

Rather than directly deriving force fields from ab initio data, a different approach toward a force field that may be applied universally to MOFs is to build upon the Universal Force Field of Rappé. ${ }^{30}$ UFF has been applied broadly to systems as far ranging as organic molecules, metal complexes and even MOFs. ${ }^{31}$ Garberoglio and Taioli found that UFF 
compared favourably to DFTB for bonded interations in MOFs. ${ }^{32}$ Allendorf and coworkers compared UFF with bespoke force fields for noble gas diffusion in HKUST-1 and ZIF-8. ${ }^{33}$ Recently, Schmidt and coworkers evaluated UFF against force fields derived using Symmetry Adapted Perturbation Theory (SAPT) $)^{34,35}$ for calculation of gas uptake in MOFs and found that while there were quantitative differences between the general and ab initio force fields, both predicted a similar ranking. ${ }^{36}$ These studies support the use of standard force fields such as UFF in the study of MOFs, however, the UFF parameters for many metals were derived from structures where a metal-carbon single bond could be identified and where there was a lack of crystal data, others were interpolated. It was the lack of UFF parameters appropriate for common MOF building blocks, most notably octahedral Copper and Zinc, that prompted the development of UFF4MOF. ${ }^{37}$

The UFF4MOF extension to UFF focussed on a training set of specific, inorganic building blocks that partially comprise several common MOFs. $\mathrm{Zn}_{4} \mathrm{O}\left(\mathrm{CO}_{2}\right)_{6}$ is the inorganic building block in the IRMOF series; ${ }^{38,39}$ paddlewheels $(\mathrm{PWs})$ may contain various metal ions, $\mathrm{Cu}$ and $\mathrm{Zn}$ are most common, as in HKUST-1, ${ }^{40}$ DMOF-1 ${ }^{41}$ and SURMOFs; ${ }^{42,43}$ and $\mathrm{M}_{3} \mathrm{O}$ oxo-centred trimers, as in the MIL-100, MIL-101 44 and MOF-235 ${ }^{45}$ MOFs. Additionally, parameters were derived for the Kuratowski-type SBU present in MFU-4 ${ }^{46,47}$ and the 1-D aluminium building block in MIL-53, ${ }^{48,49}$ which is well known for its strong breathing effect. ${ }^{50}$

The 18 UFF4MOF parameters introduced, therefore facilitate calculation of a vast number of common and important MOFs, however, an increasing number of frameworks are being synthesised using heavier elements, including Palladium, ${ }^{51}$ Silver ${ }^{52-54}$ and Ruthenium. ${ }^{55,56}$ It is clearly desirable to be able to calculate these structures rapidly, either post-synthesis or in predictive calculations. A force field that can accurately predict structures of a broad range of metal containing building blocks would allow such building blocks to be used in predicting the structures of hypothetical MOFs ${ }^{57}$ using software such as AuToGraFS ${ }^{58}$ or Zeo++. ${ }^{59}$ 
In order to derive UFF parameters applicable to MOFs featuring metals from the entire periodic table, high quality reference data is required. The Computation-Ready Experimental (CoRE) database contains 5109 3-D "MOF" structures with a pore limiting diameter greater than $2.4 \AA .{ }^{11}$ The database was compiled by an automated search of the Cambridge Structural Database (CSD) ${ }^{12}$ followed by several post-processing steps that ensured all structures in CoRE are truly 3-D connected, removed disordered atoms and solvent molecules. The search criteria used to extract structures from the CSD required at least one $M-(\mathrm{O}$, $\mathrm{N}, \mathrm{B}, \mathrm{P}, \mathrm{S}, \mathrm{C})$ bond and at least one $(\mathrm{O}, \mathrm{N}, \mathrm{B}, \mathrm{P}, \mathrm{S}, \mathrm{C})-(\mathrm{N}, \mathrm{P}, \mathrm{S}, \mathrm{C})$ bond. These criteria therefore include frameworks such as Zeolitic Imidazolate Frameworks (ZIFs), while excluding simple mineral compounds such as metal oxides and carbides.

In this paper we present a set of parameters designed to further extend UFF4MOF for the accurate calculation of framework materials from the entire periodic table. New parameters are presented for all alkali, alkaline earth metals, transition metals and lanthanide atoms observed in the CoRE database. In line with our work on UFF4MOF ${ }^{37}$ where UFF does not include atom types corresponding to the molecular geometry observed in the framework, we introduce the corresponding new atom type. All parameters presented here can be appended to the already existing UFF4MOF (and thus UFF) parameter lists and thus are readily available for any software with an UFF implementation.

\section{Methods}

\subsection{Atom Typing}

For a UFF calculation to proceed, a UFF atom type and connectivity information must be assigned to each atom in the input structure. The atom typing procedure is implemented in Python, employing the ASE library. ${ }^{60}$ For each CoRE framework structure, a first guess for 
connectivity is generated, based on the interatomic distances and covalent radii. ${ }^{61}$ Double and triple bond radii are extrapolated as being shorter by $0.15 \mathrm{~A}$ and $0.3 \mathrm{~A}$ respectively. The special cases of paddlewheels, hydrogen and halogen bonds are identified and explicitly assigned. In paddlewheels, metal-metal bonds are assigned using Cotton's values. ${ }^{62}$ Atom types are then assigned by matching the given geometry to prototypical atom types (i.e. octahedral, tetrahedral) and choosing the available atom type that best fits the bond angles and connectivity. Rings are detected using a Breadth First Search and aromaticity is detected firstly by the identification of planar rings, and secondarily by summing atomic number.

At each parameter identification, the bonding information is updated: resonant bonds for members of an aromatic ring, half bond order is assigned between oxygens and metals, and a nominal bond order (set to 0.25 ) is set between metals in a metal cluster. Finally, carbon connectivities are corrected to avoid valences greater than four. Any atoms that are not explicitly connected are assigned the parameter with the largest bond radius of those available. Using this process, only 20 out of 5109 CoRE structures contained an atom that was unable to be automatically assigned. These problematic structures are primarily structures containing $\mathrm{Cs}$ and $\mathrm{Rb}$ atoms. One third were charged structures where charge-balancing ions are equally bonded to multiple atoms, particularly $\pi$ - or haptic ligands. A list of these structures, and the atoms that are untyped is contained in the Supplementary Information.

\subsection{Parameter derivation}

The Universal Force Field ${ }^{30}$ contains both connectivity-based (valence) and nonbonded parameters: Connectivity-based parameters are the coordination number, single bond radius, and bond angle. The bond length between any two atoms $i$ and $j, r_{i j}$, is the sum of each bond radius, plus a correction for bond-order (i.e., double, triple, resonant..., supplied by the user) and a fixed electronegativity correction $\left(\mathrm{Eq} 2\right.$ in $\left.\operatorname{Re}^{30}\right)$. Nonbonded parameters 
include the Lennard-Jones potential parameters and a scaling parameter $\zeta$ that allows finetuning the shape of the potential. For most elements, a value of $\zeta=12$ is chosen, coinciding with the Lennard-Jones potential.

Following the UFF atom type formalism, we consider an atom type to be entirely defined by specification of the bond radius and angle, all other parameters being equal for atom types of the same element. We do not re-derive any non-bonded parameters, leaving them the same as the original UFF values. The parameter derivation procedure is broadly similar to that outlined in our previous work, ${ }^{37}$ where bond angles are determined by observation and radii are determined by fitting to reference data. All calculations were carried out using the General Utility Lattice Program (GULP). ${ }^{63,64}$ As in the original derivation of UFF parameters, no partial charges were employed ${ }^{30}$ in either cluster or periodic calculations. Cluster models were cut from the reference crystallographic information files and saturated with hydrogen atoms as needed. For each cluster model, the geometry was optimised, changing the prototype new parameter (bond radius) in $0.02 \AA$ increments from $0.9-2.3 \AA$, the bond radius was then chosen to minimise the error in metal-metal and metal-oxygen bond distances. In the case of alkali and alkaline earth metals the scan range was extended to 0.9 - 2.6A. All scan data is presented in the Supplementary Information. Parameters are named according to the standard UFF convention, whereby the first two characters correspond to the chemical symbol, using an underscore as the second character in the case of a single character chemical symbol. The third character symbolizes the geometry, in addition to those geometries already defined by Rappé, ${ }^{30}$ we add $8=$ cubic antiprism. The final two columns are used to indicate alternate parameters, such as oxidation state. In these columns we employ the letter "f" to indicate framework parameter and leave the (assumed positive) oxidation state in the final column.

The original UFF4MOF added two new oxygen atom types (O_3_f and O_2_z) that were straightforwardly derived as hybrids of the existing (Rappé) UFF atom types. In a similar 
fashion, we propose a hybrid sulfur parameter, S_3_f, which uses the $0.854 \AA$ bond radius of Rappé's S_2 parameter, but has a tetrahedral angle. An example of a structure where this parameter yields better agreement with the experimental structure (compared to the Rappé parameter S-3+6, which has a significantly longer bond radius of $1.027 \AA$ ) is CSD refcode LUNBAX. ${ }^{65}$

\subsection{Breathing and solvent-stabilized MOFs}

The solvent removal procedure employed in generating the CoRE database does not consider whether the removed solvent molecules are essential to maintaining the structural integrity of the framework. A notable case of such stabilization by solvent molecules is the well-known MIL-53, where the narrow pore structure is stabilized by hydrogen bonds between (i) solvent oxygen and hydrogen from the $\left[\mathrm{AlO}_{4}(\mathrm{OH})_{2}\right]$ octahedra, (ii) solvent hydrogen molecules and framework oxygen atoms and (iii) solvent oxygen and solvent hydrogen. ${ }^{66,67}$ In these cases, naïve optimization of the solvent-free structure, that fails to adequately consider the effects of temperature and dispersion, will result in a different structure being obtained (the large pore structure for MIL-53). Where geometry optimization produced a structure with any cell parameter deviating by $>20 \%$ from the original CoRE structure, we retrieved the original structure from the CCSD to confirm adsorbed molecules as the cause of the deviation and we exclude them from analysis in this work. We have manually repaired many of these frameworks and we will consider them in a future work. After this exclusion, we are left with 4892 frameworks. 


\section{Results and Discussion}

According to Chung et al., the CoRE database contains more than 50 distinct types of metal and lanthanide clusters. ${ }^{11}$ After typing analysis applied to alkali, alkaline earth, transition metals and lanthanides, we identify 163 distinct metal atom environments. If restricted to environments that occur in at least five different structures, this reduces to 105 distinct environments. The distribution of environments is shown in Figure 1.

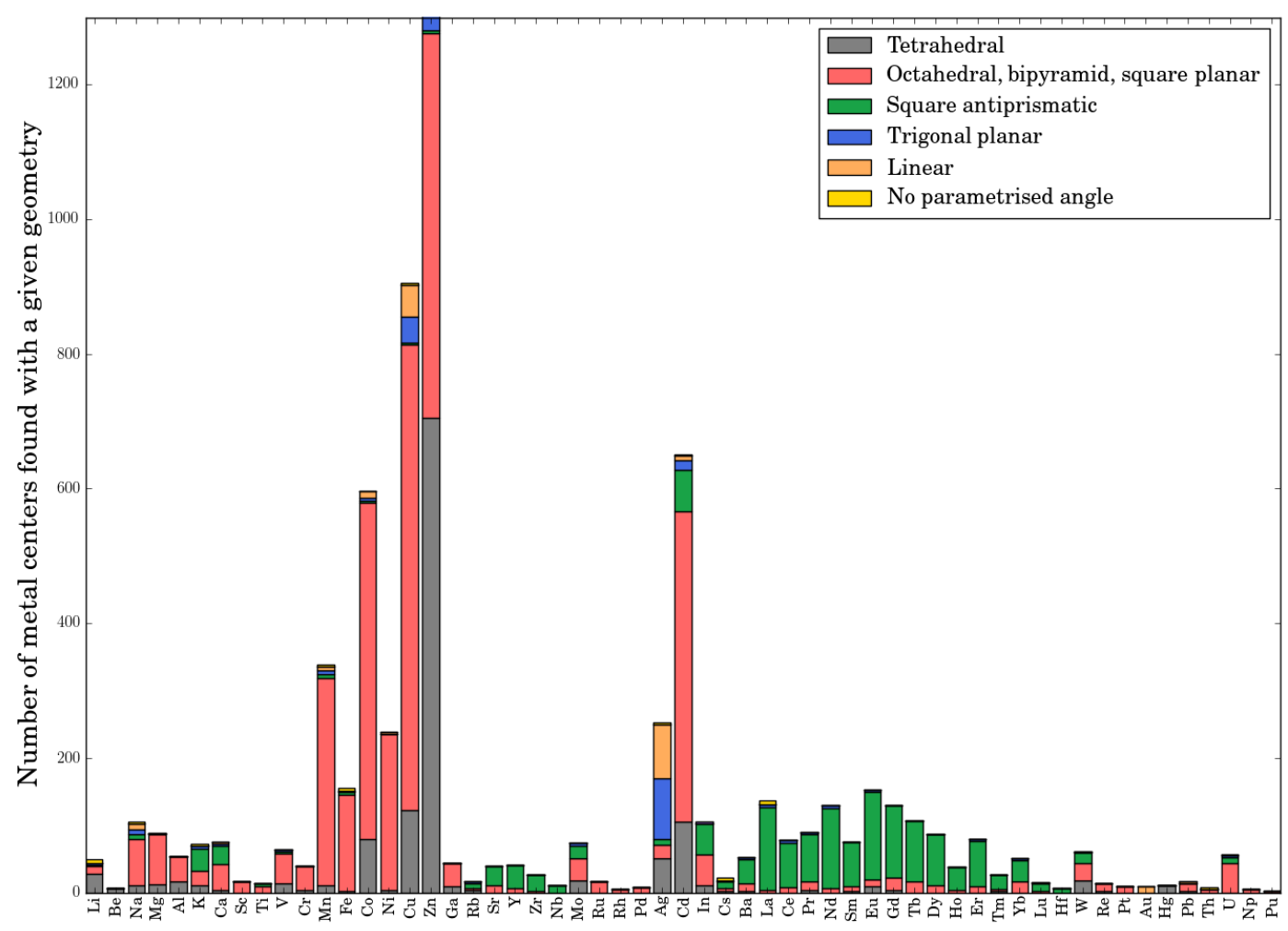

Figure 1: Occurrences of metal, alkali and alkaline earth metals in the CoRE database, coloured by bond angle.

From these 105 environments, 14 were adequately covered by Rappé's UFF parameters, 12 had parameters previously derived in UFF4MOF, ${ }^{37}$ in two cases an existing tetrahedral parameter could be applied to an antiprism geometry and in six cases there was no suitably regular structure from which to derive a new parameter. Consequently there were 71 
environments for which a UFF parameter could be derived. These 71 new UFF4MOF parameters are shown in Table 1. For each of the 71 environments a single model structure from CoRE was chosen to use as the basis for parameter derivation. The structure that best matched the "ideal" environment (e.g: perfect planarity and 120 degrees angles for a trigonal planar environment.) was chosen, and in the case that more than one structure was equally suitable, the one with phenyl-based linkers was preferred, ensuring that the metallic cluster was consistently well described by a cutout. A complete list of the detected environments and the CCSD refcodes of the structures used to derive the new UFF parameters (i.e. the training set) is contained in the Table S1.

Table 1: List of the new force field parameters (extension to UFF4MOF) introduced to UFF. When UFF already includes a parameter for the given element and angle, this parameter's radius is included for comparison purposes

\begin{tabular}{|c|c|c|c|c|c|}
\hline \multirow[b]{2}{*}{ New atom types } & \multirow[b]{2}{*}{ Angle $\theta_{0}$ (degrees) } & \multirow[b]{2}{*}{$\begin{array}{l}\text { Coordination } \\
\text { number }\end{array}$} & \multirow{2}{*}{$\begin{array}{l}\text { UFF4MOF } \\
\text { Bond } r_{I}(\AA)\end{array}$} & \multicolumn{2}{|l|}{ Rappé's UFF } \\
\hline & & & & UFF Atom type & Bond $r_{I}(\AA)$ \\
\hline Li3f2 & 109.47 & 4 & 1.28 & & \\
\hline Na3f2 & 109.47 & 4 & 1.623 & & \\
\hline $\mathrm{Na} 4 \mathrm{f} 2$ & 90.0 & 4 & 1.79 & & \\
\hline Mg6f3 & 90.0 & 6 & 1.525 & & \\
\hline $\mathrm{Al} 3 \mathrm{f} 2$ & 109.47 & 4 & 1.28 & $\mathrm{Al} 3$ & 1.244 \\
\hline K_3f2 & 109.47 & 4 & 2.38 & & \\
\hline K_4f2 & 90.0 & 4 & 2.01 & & \\
\hline Ca3f2 & 109.47 & 4 & 1.705 & & \\
\hline V_3f2 & 109.47 & 4 & 1.12 & $\mathrm{~V} \_3+5$ & 1.402 \\
\hline Mn1f1 & 180.0 & 2 & 1.38 & & \\
\hline Mn3f2 & 109.47 & 4 & 1.18 & & \\
\hline $\mathrm{Mn} 8 \mathrm{f} 4$ & 109.47 & 8 & 1.52 & & \\
\hline Co1f1 & 180.0 & 2 & 1.28 & & \\
\hline Cu1f1 & 180.0 & 2 & 1.24 & & \\
\hline $\mathrm{Cu} 2 \mathrm{f} 2$ & 120.0 & 3 & 1.11 & & \\
\hline Cu3f2 & 109.47 & 4 & 1.19 & $\mathrm{Cu} 3+1$ & 1.302 \\
\hline Zn1f1 & 180.0 & 2 & 1.30 & & \\
\hline $\mathrm{Zn} 2 \mathrm{f} 2$ & 120.0 & 3 & 1.30 & & \\
\hline
\end{tabular}




\begin{tabular}{|c|c|c|c|c|c|}
\hline \multirow[b]{2}{*}{ New atom types } & \multirow[b]{2}{*}{ Angle $\vartheta_{0}$ (degrees) } & \multirow[b]{2}{*}{$\begin{array}{l}\text { Coordination } \\
\text { number }\end{array}$} & \multirow{2}{*}{$\begin{array}{l}\text { UFF4MOF } \\
\text { Bond } r_{I}(\AA)\end{array}$} & Rappé's UFF & \\
\hline & & & & Bond $r_{I}(\AA)$ & \\
\hline Ga3f2 & 109.47 & 4 & 1.15 & $\mathrm{Ga} 3+3$ & 1.26 \\
\hline Ga6f3 & 90.0 & 6 & 1.48 & & \\
\hline Sr8f4 & 109.47 & 8 & 1.82 & & \\
\hline Y_6f3 & 90.0 & 6 & 1.60 & & \\
\hline Y_8f4 & 109.47 & 8 & 1.68 & Y_3+3 & 1.698 \\
\hline Zr8f4 & 109.47 & 8 & 1.68 & $\mathrm{Zr} 3+4$ & 1.564 \\
\hline $\mathrm{Nb} 8 \mathrm{f} 4$ & 109.47 & 8 & 1.37 & $\mathrm{Nb} 3+5$ & 1.473 \\
\hline Mo3f2 & 109.47 & 8 & 1.24 & $\mathrm{Mo} 3+6$ & 1.484 \\
\hline Mo4f2 & 90.0 & 4 & 1.40 & Mo6+6 & 1.467 \\
\hline $\operatorname{Mo8f4}$ & 109.47 & 8 & 1.28 & Mo3+6 & 1.484 \\
\hline Tc4f 2 & 90.0 & 4 & 1.32 & 1.322 & \\
\hline $\mathrm{Ru} 4 \mathrm{f} 2$ & 90.0 & 4 & 1.32 & Ru6+2 & 1.478 \\
\hline Pd6f3 & 90.0 & 6 & 1.19 & $\mathrm{Pd} 4+2$ & 1.338 \\
\hline Ag1f1 & 180.0 & 2 & 1.22 & $\operatorname{Ag} 1+1$ & 1.386 \\
\hline $\operatorname{Ag} 2 f 2$ & 120.0 & 3 & 1.34 & & \\
\hline Ag3f2 & 109.47 & 4 & 1.48 & & \\
\hline $\operatorname{Ag} 4 \mathrm{f} 2$ & 90.0 & 4 & 1.51 & & \\
\hline Cd1f1 & 180.0 & 2 & 1.40 & & \\
\hline $\mathrm{Cd} 3 \mathrm{f} 2$ & 109.47 & 4 & 1.29 & $\mathrm{Cd} 3+2$ & 1.403 \\
\hline $\mathrm{Cd} 4 \mathrm{f} 2$ & 90.0 & 4 & 1.46 & & \\
\hline $\mathrm{Cd} 8 \mathrm{f} 4$ & 109.47 & 8 & 1.64 & $\mathrm{Cd} 3+2$ & 1.403 \\
\hline $\operatorname{In} 3 \mathrm{f} 2$ & 109.47 & 4 & 1.33 & $\operatorname{In} 3+3$ & 1.459 \\
\hline In6f3 & 90.0 & 6 & 1.53 & & \\
\hline $\operatorname{In} 8 f 4$ & 109.47 & 8 & 1.53 & $\operatorname{In} 3+3$ & 1.459 \\
\hline Ba3f2 & 109.47 & 4 & 2.04 & & \\
\hline $\mathrm{La} 8 \mathrm{f} 4$ & 109.47 & 8 & 1.66 & $\mathrm{La} 3+3$ & 1.943 \\
\hline Ce8f4 & 109.47 & 8 & 1.76 & & \\
\hline $\operatorname{Pr} 8 \mathrm{f} 4$ & 109.47 & 8 & 1.83 & & \\
\hline $\mathrm{Nd} 8 \mathrm{f} 4$ & 109.47 & 8 & 1.78 & & \\
\hline Sm8f4 & 109.47 & 8 & 1.78 & & \\
\hline Eu6f3 & 90.0 & 6 & 1.60 & Eu6+3 & 1.771 \\
\hline Eu8f4 & 109.47 & 8 & 1.74 & & \\
\hline Gd6f3 & 90.0 & 6 & 1.55 & $\mathrm{Gd} 6+3$ & 1.735 \\
\hline Gd8f4 & 109.47 & 8 & 1.70 & & \\
\hline
\end{tabular}




\begin{tabular}{|c|c|c|c|c|c|}
\hline \multirow[b]{2}{*}{ New atom types } & \multirow[b]{2}{*}{ Angle $\vartheta_{0}$ (degrees) } & \multirow[b]{2}{*}{$\begin{array}{l}\text { Coordination } \\
\text { number }\end{array}$} & \multirow{2}{*}{$\begin{array}{l}\text { UFF4MOF } \\
\text { Bond } r_{I}(\AA)\end{array}$} & Rappé's UFF & \\
\hline & & & & Bond $r_{I}(\AA)$ & \\
\hline $\mathrm{Tb} 8 \mathrm{f} 4$ & 109.47 & 8 & 1.64 & & \\
\hline Dy6f3 & 90.0 & 6 & 1.58 & Dy $6+3$ & 1.710 \\
\hline Dy8f4 & 109.47 & 8 & 1.70 & & \\
\hline Ho8f4 & 109.47 & 8 & 1.70 & & \\
\hline Er8f4 & 109.47 & 8 & 1.64 & & \\
\hline $\operatorname{Tm} 8 \mathrm{f} 4$ & 109.47 & 8 & 1.67 & & \\
\hline Yb6f3 & 90.0 & 6 & 1.45 & & \\
\hline Yb8f4 & 109.47 & 8 & 1.62 & & \\
\hline Lu8f4 & 109.47 & 8 & 1.66 & & \\
\hline Hf8f4 & 109.47 & 8 & 1.46 & $\mathrm{Hf} 3+4$ & 1.61 \\
\hline W_3f2 & 109.47 & 4 & 1.16 & $\mathrm{~W} \_3+4, \mathrm{~W} \_3+6$ & $1.380,1.526$ \\
\hline W_4f2 & 90.0 & 4 & 1.345 & $\mathrm{~W} \_6+6$ & 1.392 \\
\hline $\mathrm{W} \_8 f 4$ & 109.47 & 4 & 1.27 & $\mathrm{~W} \_3+4, \mathrm{~W} \_3+6$ & $1.380,1.526$ \\
\hline Re6f3 & 90.0 & 4 & 1.23 & Re6+5 & 1.314 \\
\hline Os4f2 & 90.0 & 4 & 1.24 & 1.372 & \\
\hline Pt4f2 & 90.0 & 4 & 1.125 & $\mathrm{Pt} 4+2$ & 1.364 \\
\hline Au1f1 & 180.0 & 2 & 1.11 & & \\
\hline Hg3f2 & 109.47 & 4 & 1.248 & & \\
\hline $\mathrm{Pb} 4 \mathrm{f} 2$ & 90.0 & 4 & 1.67 & & \\
\hline U_6f3 & 90.0 & 6 & 1.65 & U_6+4 & 1.684 \\
\hline U_8f4 & 109.47 & 8 & 1.73 & & \\
\hline S_3_f & 109.47 & 3 & 0.854 & $\mathrm{~S} \_3+6$ & 1.027 \\
\hline
\end{tabular}

Because the atom typing process relies on comparison with idealised reference geometries, the inclusion of a less than complete set of reference geometries will alter the assigned atom types. To consider only a single bond angle as a simple example; an angle of $100^{\circ}$ may be typed as either octahedral $\left(90^{\circ}\right)$ or tetrahedral $\left(109.47^{\circ}\right)$. When a parameter is available for both environments, the better fitting one, where all angles are fitted with the least deviation is chosen. In the simple 1-D case above, the tetrahedral parameter (which has an error of $9.47^{\circ}$ ) vs. an error of $10^{\circ}$ in the octahedral case), will be chosen. However, if only an octahedral parameter is available, then this parameter will be assigned with only 
marginally less confidence. Therefore, to illustrate the performance of the new UFF4MOF parameters, we consider three distinct sets of CoRE MOFs: Firstly all structures were typed using UFF4MOF parameters (those developed so far and the extension currently presented here), but any structures containing non-Rappé parameters were discarded. This resulted in 1894 structures being retained and 1761 of these (that were not missing essential solvent molecules) were optimized. Secondly, all structures were typed using only the original UFF parameters. A total of 2309 structures were successfully typed (of which 2281 were optimized). The difference between these two subsets, shows that 415 structures contained atomic environments that were able to be typed more than one way and are better typed using the UFF4MOF parameter. Finally, structures were typed using the complete set of UFF + UFF4MOF parameters. 5089 of the 5109 CoRE structures were successfully typed with these parameters and 4892 were optimized. The difference between the second and third sets immediately illustrates the utility of the UFF4MOF parameters, raising the number of calculable CoRE systems from less than half, to over $99.5 \%$.

To assess the accuracy of the new parameters, fully periodic classical, constant pressure geometry optimisations were undertaken from each typed structure, simultaneously optimising both the atomic positions and lattice vectors. The molecular connectivity was kept constant, and all 1-2 and 1-3 Coulomb interactions were excluded (i.e. molmec option in GULP), all other cutoffs were left at their default values. No symmetry was imposed - i.e. all calculations took place in P1 spacegroup.

Cell angles were largely the same as their initial values (where all three cell angles were $90^{\circ}$, these were constrained by specifying orthorhombic cell constraints) and so we consider only the lengths of the $a, b$ and $c$ lattice vectors. The distribution of these errors is shown in Figures $2-4$.

Employing the new UFF4MOF parameters (Figure 2), 76.5\% of of cell parameters are within $5 \%$ of the reference value, and $95.0 \%$ are within $10 \%$. Considering absolute errors, $96.8 \%$ of cell parameters deviate less than $2 \AA$ of the experimental reference value. For 


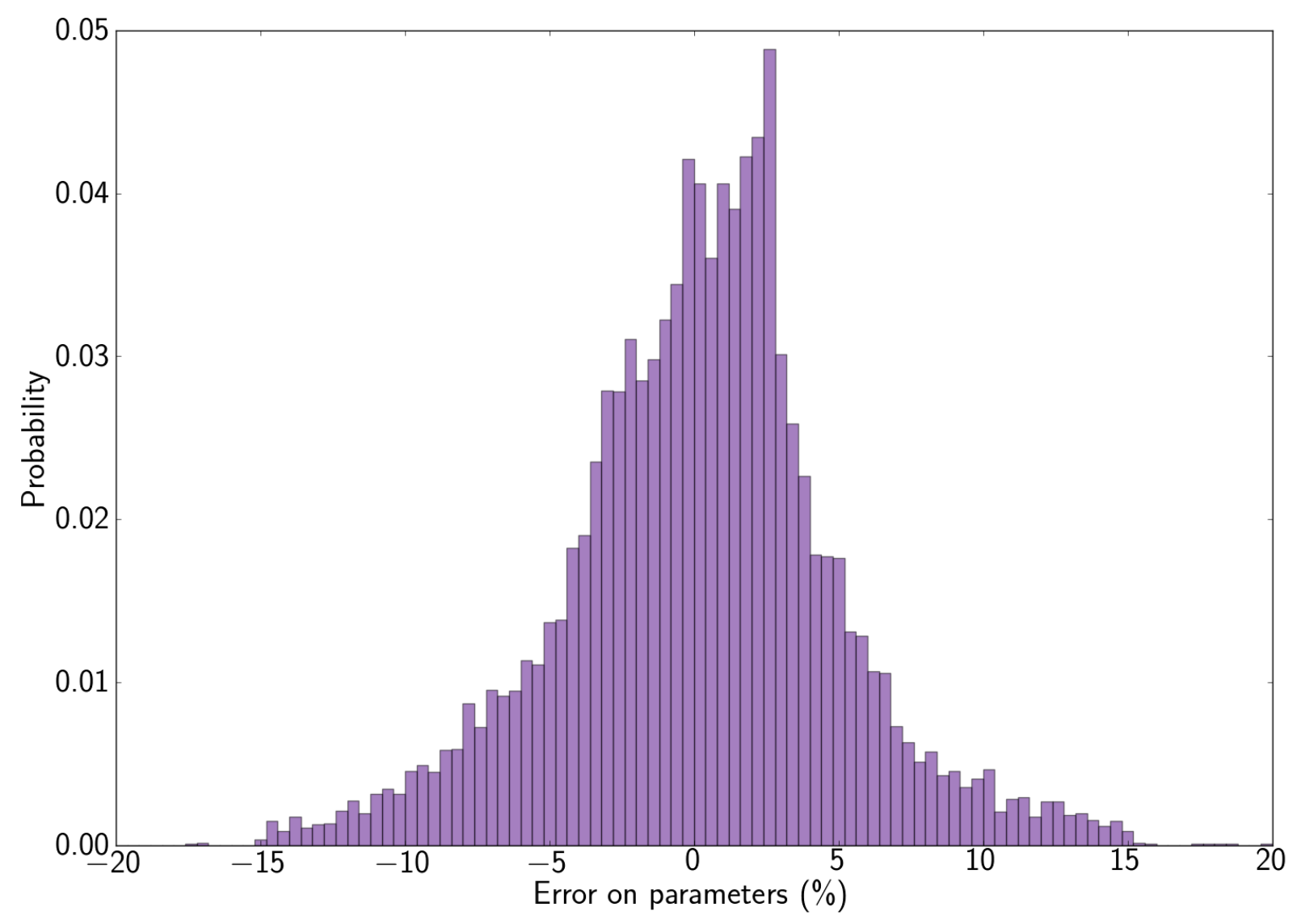

Figure 2: Error in cell parameters, calculated as $\left(X_{U F F}-X_{E x p}\right)(a, b, c)$ for $4892 \mathrm{CoRE}$ structures typed and calculated employing UFF4MOF parameters. 


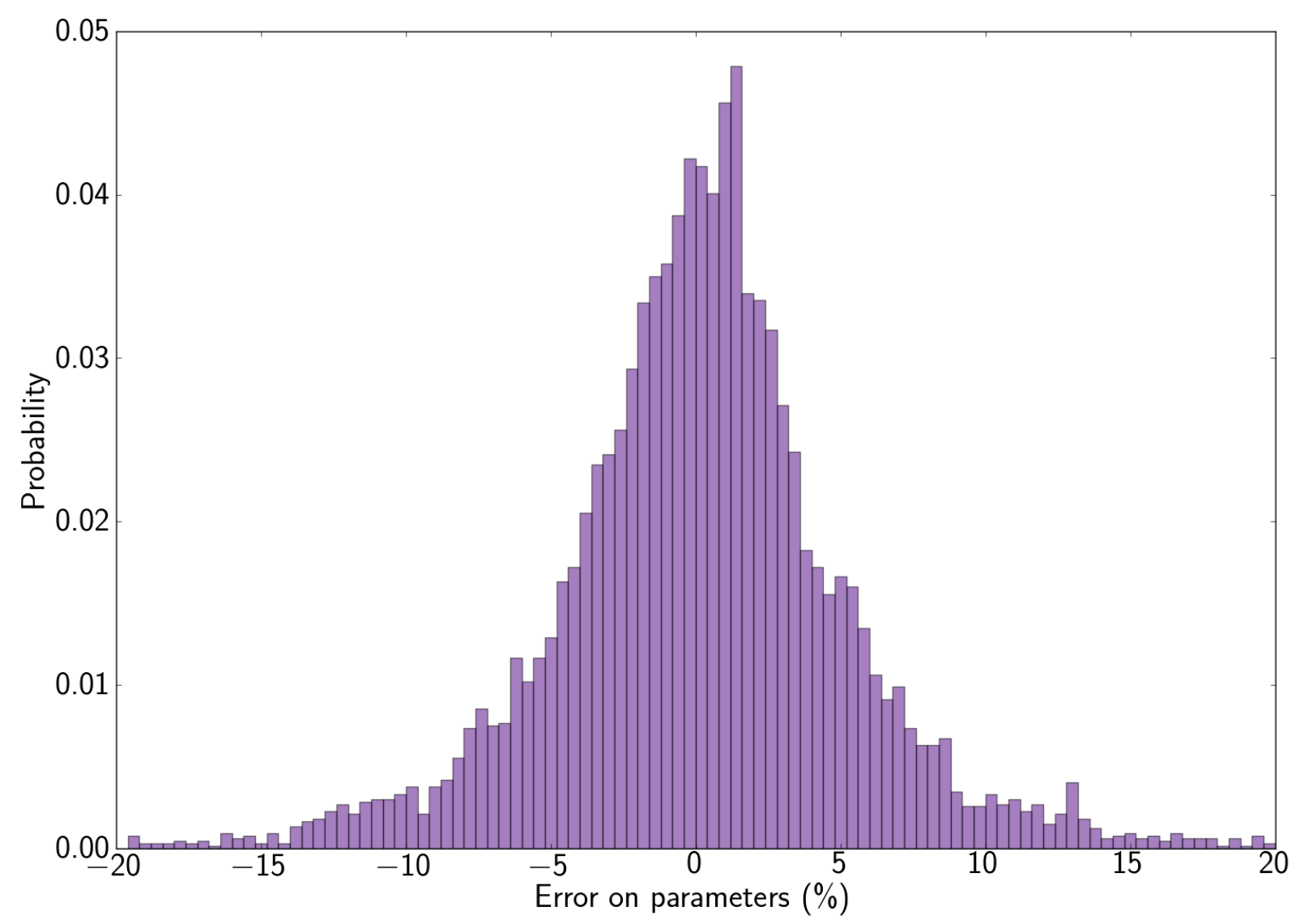

Figure 3: Error in cell parameters, $(a, b, c)$ for 2281 CoRE structures typed and calculated employing only parameters from the original UFF set. 


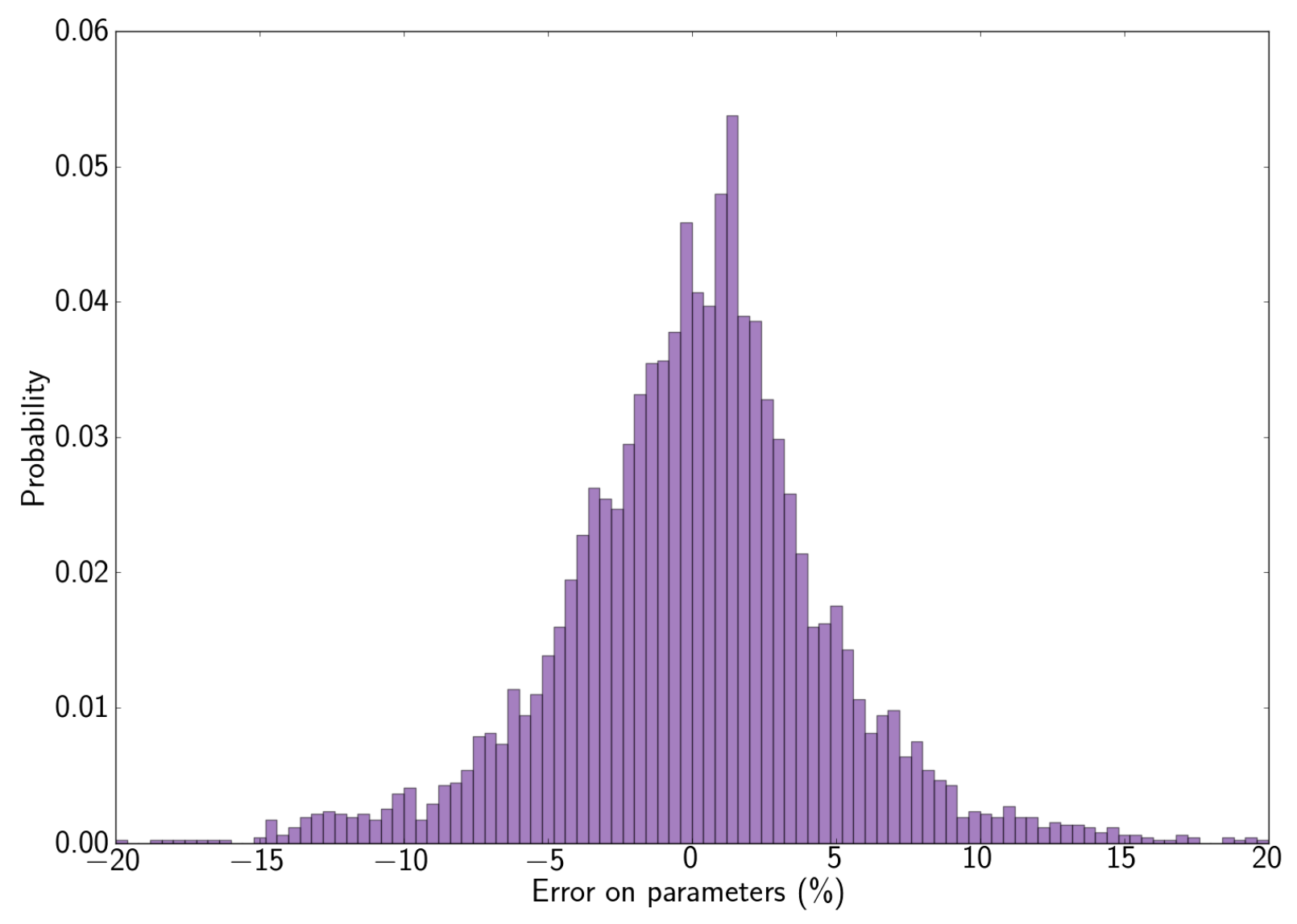

Figure 4: Error in cell parameters, $(a, b, c)$ for 1761 CoRE structures typed using UFF + UFF4MOF parameters, but calculated employing only parameters from the original UFF set 
the structures calculated using only Rappé's UFF parameters, the distribution in errors is broadly similar, with 73.2 and $91.4 \%$ of cell parameters being within 5 and $10 \%$ of the reference value when structures were typed using only Rappé's parameters (2281 structures). These figures rise slightly to 76.6 and $94.3 \%$ when structures are typed using both UFF and UFF4MOF parameters, but optimised using only the original UFF, discarding any structures that require UFF4MOF parameters, however, only 1761 structures are capable of being optimized in this case. Comparing only the two sets of calculations that employed UFF parameters only, the modest increase in accuracy when atoms are typed using the superset of UFF4MOF and Rappé's parameters, gives an indication of the influence of mistyping 'intermediate' atomic environments, where metal atoms may be typed as either octahedral or tetrahedral.

\subsubsection{Limits on accuracy}

In our previous work, ${ }^{37}$ we noted cases in which a UFF4MOF optimization might generate atomic positions that deviate somewhat from the local reference structure, while the overall structure is still fundamentally correct. This occurs when the number of angle terms defined by the connectivity is sufficient to 'overwhelm' one or more distance terms. In general, the number of angle terms in highly-connected metal oxide SBUs will tend to force these structures to their 'ideal' geometries. A particular example of this occurs in paddlewheel structures, shown in Figure 5 where the four or eight (in the case of a pillared paddlewheel) $90^{\circ}$ angle terms around each metal atom force the coplanarity of the metal and its four oxygen neighbours, such that the paddlewheel motif adopts $D_{4 h}$ symmetry. In this case, the metal atoms deviate by up to $0.3 \AA$ from their reference positions, but the oxygen positions are correct and the overall unit cell is also correct in two dimensions (assuming the metaloxygen axes lie parallel with two cell vectors) as shown in Figure 6. Some error is made in the third dimension (along the pillar), though this is partially compensated by an opposite 
error in the metal - pillar (nitrogen) distance. The follow-on effect of this local deviation on the cell parameters is thus variable, depending on the framework topology, the degree of distortion in the SBU (w.r.t the ideal, or highest symmetry SBU) and the identity of neighbouring SBUs.

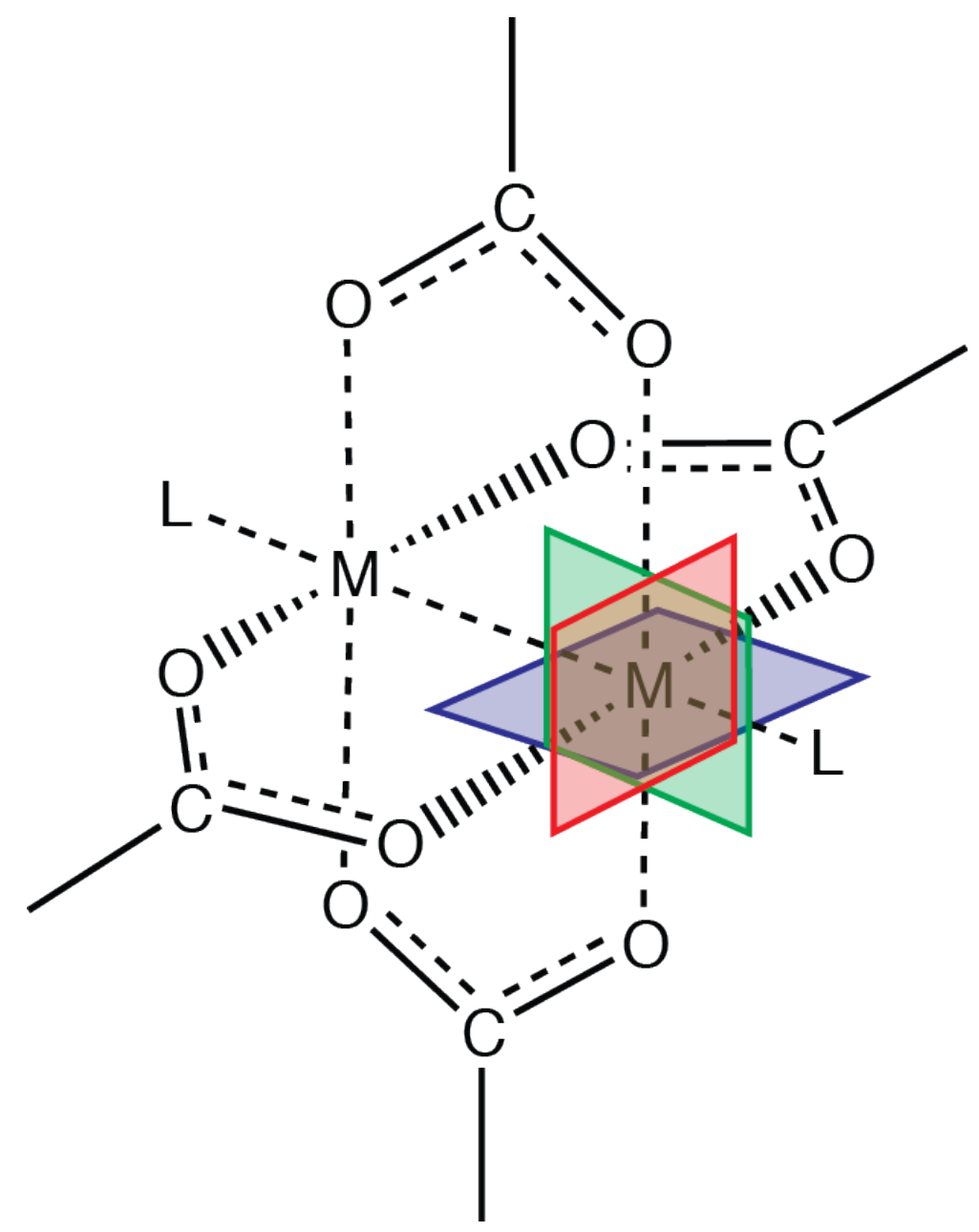

Figure 5: Pillared paddlewheel, indicating the three mutually perpendicular planes centred on each (only one shown) metal atom. The planes are forced by eight O-M-L angles around each octahedral $\left(90^{\circ}\right)$ metal atom.

\subsection{Atomic positions}

While the small deviation of the lattice parameters from the experimental reference structures gives a high degree of confidence in the quality of the structure, it is also useful to 


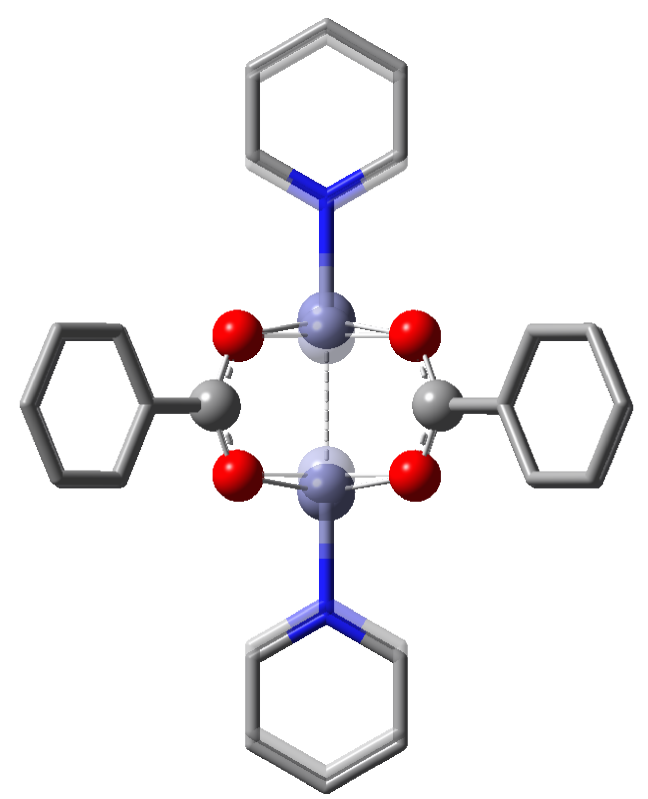

Figure 6: Pillared Zn paddlewheel, with UFF4MOF optimized structure (pale) shown superimposed on DFT (BP86/TZP) optimized structure, showing the contraction of the Zn-Zn bond distance.

consider the atomic positions. The UFF4MOF-optimized structures can be compared with the reference CoRE structures, by first scaling the optimized structure to the cell dimensions of the reference structure and then computing the RMSD of the atoms in each structure.

Recalling the tendency to converge to idealized geometries, we consider the accuracy of the atomic positions overall, for metal atoms specifically, for oxygen atoms that have a metal neighbour (which excludes oxygen atoms on linker molecules) and all other atoms (i.e. non-metal and not oxygens bound to metal atoms), which we assume to represent the linkers. The RMSD of each of these atom groups is shown in Figure 7. The mean RMSD for all atoms is $0.653 \AA$, very close to that of the linkers, $0.652 \AA$ and the distribution of the RMSD for all atoms is also largely defined by that of the linkers. Deviation of the linker atom positions is largely caused by flexibility in the linkers, which may rotate or flex without affecting the overall structure quality. By contrast, the atomic positions of the metal atoms and metal-bound oxygen atoms are somewhat more tightly conserved, with mean RMSD values of 0.463 and $0.579 \AA$ respectively. 


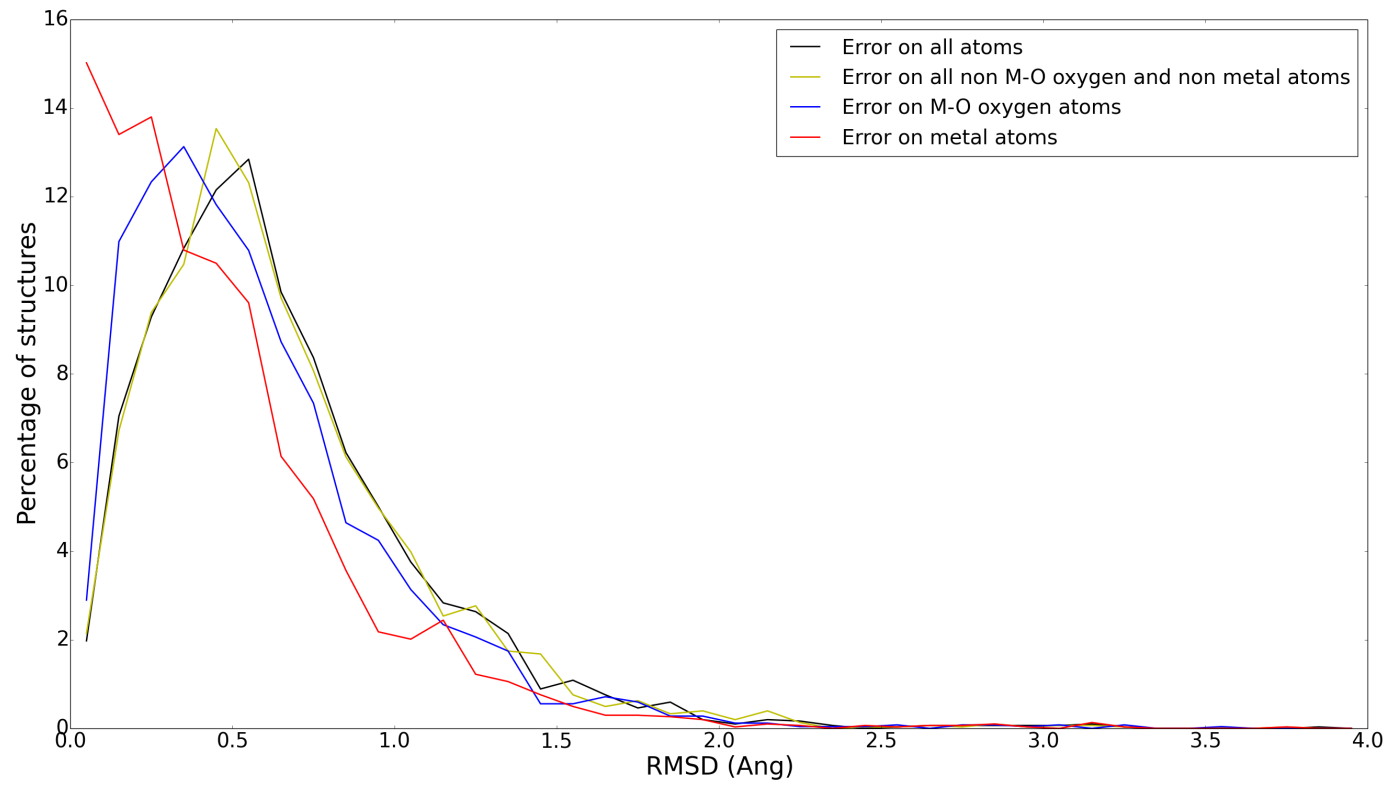

Figure 7: RMSD of UFF4MOF optimized atom positions with respect to the CoRE structures

To gain a better understanding of the accuracy of the overall structure and remove the error associated with linker flexibility, we further consider the accuracy of all bond lengths in each framework. In this case, we compare the unscaled bond lengths emanating from each atom in each structure. We consider firstly all bonds containing a metal atom (i.e. M-X, X may be either metal or non-metal), all non-metal bonds (i.e. X-Y, neither X or Y may be metal) and finally, all bonds. The RMSD for each of the three CoRE subsets in Figures 2 4 are shown in Figure 8. From this it becomes clear that the non-metal bonds are actually very well described in all cases, with a mean RMSD of $0.100 \AA$ using UFF4MOF, vs. $0.108 \AA$ for those structures typed and calculated using UFF. A larger improvement is seen when metal bonds are considered, with the mean RMSD for metal-containing bonds calculated by UFF4MOF, $0.158 \AA$ reduced from a value of $0.178 \AA$ observed for both UFF subsets.

A further indication of the quality of the structures is given by the volumetric and gravi- 

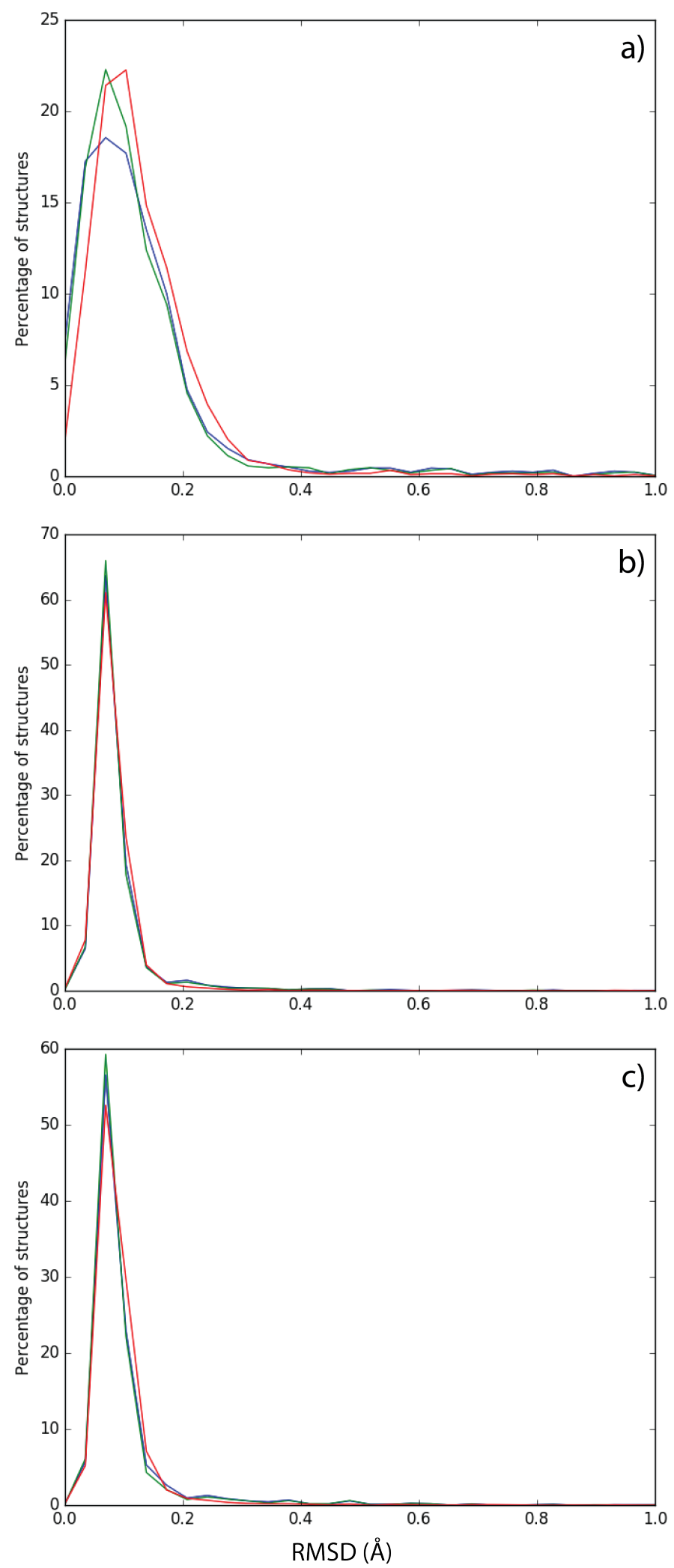

Figure 8: RMSD of UFF4MOF optimized bond lengths with respect to the CoRE structures. a) shows all metal containing (M-X) bonds, b) shows all bonds without a metal atom and c) shows all bonds. The RMSD for 4892 CoRE structures typed and optimized using the full set of UFF4MOF parameters is shown in red, RMSD for 2281 CoRE structures typed and calculated employing only parameters f2dm the original UFF are shown in green and RMSD for 1761 CoRE structures typed using UFF + UFF4MOF parameters, but calculated employing only UFF is shown in blue. 
metric surface areas, which may be directly be compared to the analysis of Chung et al. ${ }^{11}$ As can be observed in Figure 9, the pre- and post-optimisation surface areas follow a very similar distrubution, further supporting the quality of the optimized structures.
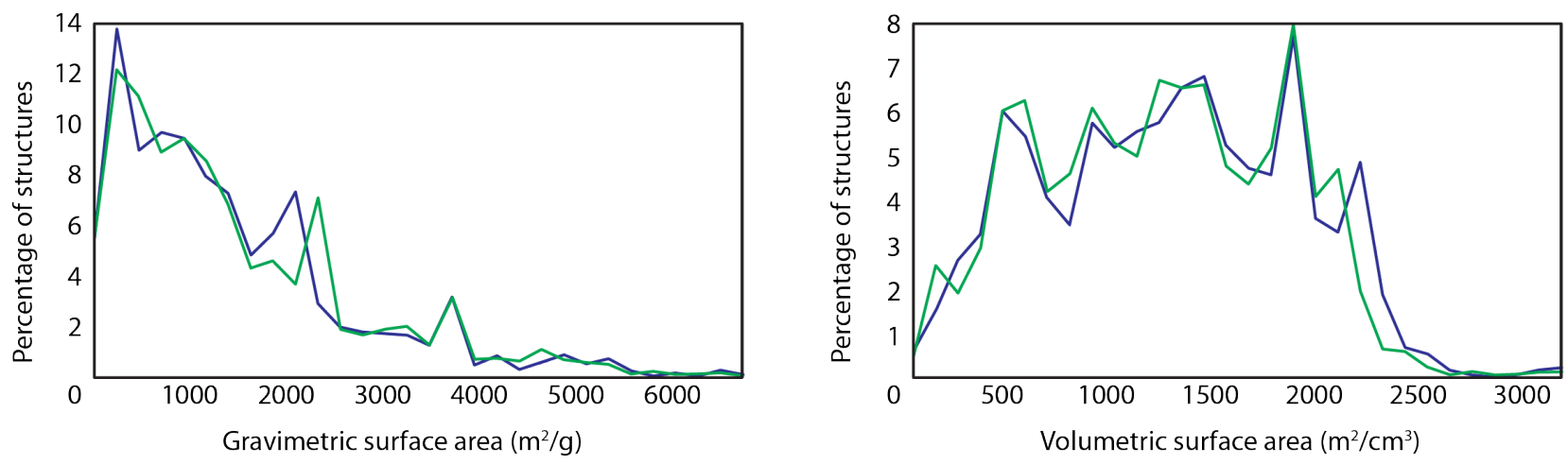

Figure 9: Gravimetric and volumetric surface areas of CoRE structures, as provided (blue) and after re-optimization using UFF4MOF in GULP (green). All surface areas were calculated using Zeo $++{ }^{59}$ with a probe radius of 1.86 (corresponding to $\mathrm{N}_{2}$ ).

\section{Atoms not found in CoRE}

Noting some of the 'holes' in the newly-developed UFF4MOF parameters derived from CoRE environments, non-periodic Technetium ${ }^{68}$ and Osmium $^{69}$ paddlewheel structures were used to derive square planar parameters (bond angles of $90^{\circ}$ ). Bond orders between metal atoms are taken from Cotton et al. ${ }^{62}$ The atomic radius obtained for Technetium is $1.32 \AA$; almost identical to the $r_{i}$ of 1.322 in Tc6+5 parameter from Rappé. Thus, its use is not warranted. On the contrary, the Osmium parameter Os4f2 has a distinct value of 1.24 compared to 1.372 in the UFF parameters, and should be used instead to accurately describe Osmium paddlewheel environments. 


\subsection{Computationally Predicted MOFs}

The CoRE database contains only 5109 experimentally realised MOF structures representing over 350 unique topologies, ${ }^{11}$ by contrast the large scale screening study of Wilmer et al. scanned 137,953 hypothetical MOFs, but only employed 5 inorganic building blocks resulting in six topologies being encountered and more than $90 \%$ of structures were of the primitive cubic pcu topology. Several other authors have since undertaken smaller screening studies of hypothetical MOFs, e.g. Bao et al. who used an evolutionary algorithm to search nine topologies for methane capacity ${ }^{70}$ Gomez-Gauldron et al. scanned four nets that are compatible with Zirconium-based building blocks and several ditopic and tetratopic linkers ${ }^{71}$ also for methane deliverable capacity, highlighting subtle effects of the order of triple bonds and phenyl groups in same length linker molecules and Banerjee et al. scanned 125,000 MOFs for their $\mathrm{Xe} / \mathrm{Kr}$ selectivity. ${ }^{72}$

It therefore seems clear that there are many millions of synthetically feasible, but as yet hypothetical MOFs that may be subjected to calculation. Computational screening of vast numbers of hypothetical framework materials, within some set of constraints, in order to identify synthetic targets with desired properties is the most efficient means to identify the best framework material(s) for any given application. Additionally, growing interest in more exotic MOFs - MOFs that contain heavy and $f$-block elements, useful for their photoluminescence properties, means that such screening studies need to reach the entire periodic table. In order to illustrate the capacity of such a screening study, and noting the interest in chemically functionalizing framework linkers ${ }^{73-75}$, we begin with the CoRE database and functionalize each structure by replacing either 10 or 30 percent of linker hydrogen atoms with either a fluoride or an amine functional group. The effect on the available pore fraction is shown in Figure 10. The immediate effect of all functionalization, is to reduce the available pore volume fraction. Notably, the number of structures now having $0 \%$ available pore volume rises from $15 \%$ in CoRE, to $26 \%$ and $28 \%$ when $10 \%$ and $30 \%$ of hydrogen atoms are replaced with fluoride respectively. Similarly, replacing 10 and $30 \%$ of linker hydrogen 
atoms with amine functional groups raises the number of structures with fully blocked pores to 28 and $34 \%$ respectively. The gravimetric and volumetric surface areas, shown in Figure 11 tell a very similar story with approximately $20 \%$ of functionalized structures having zero surface area.

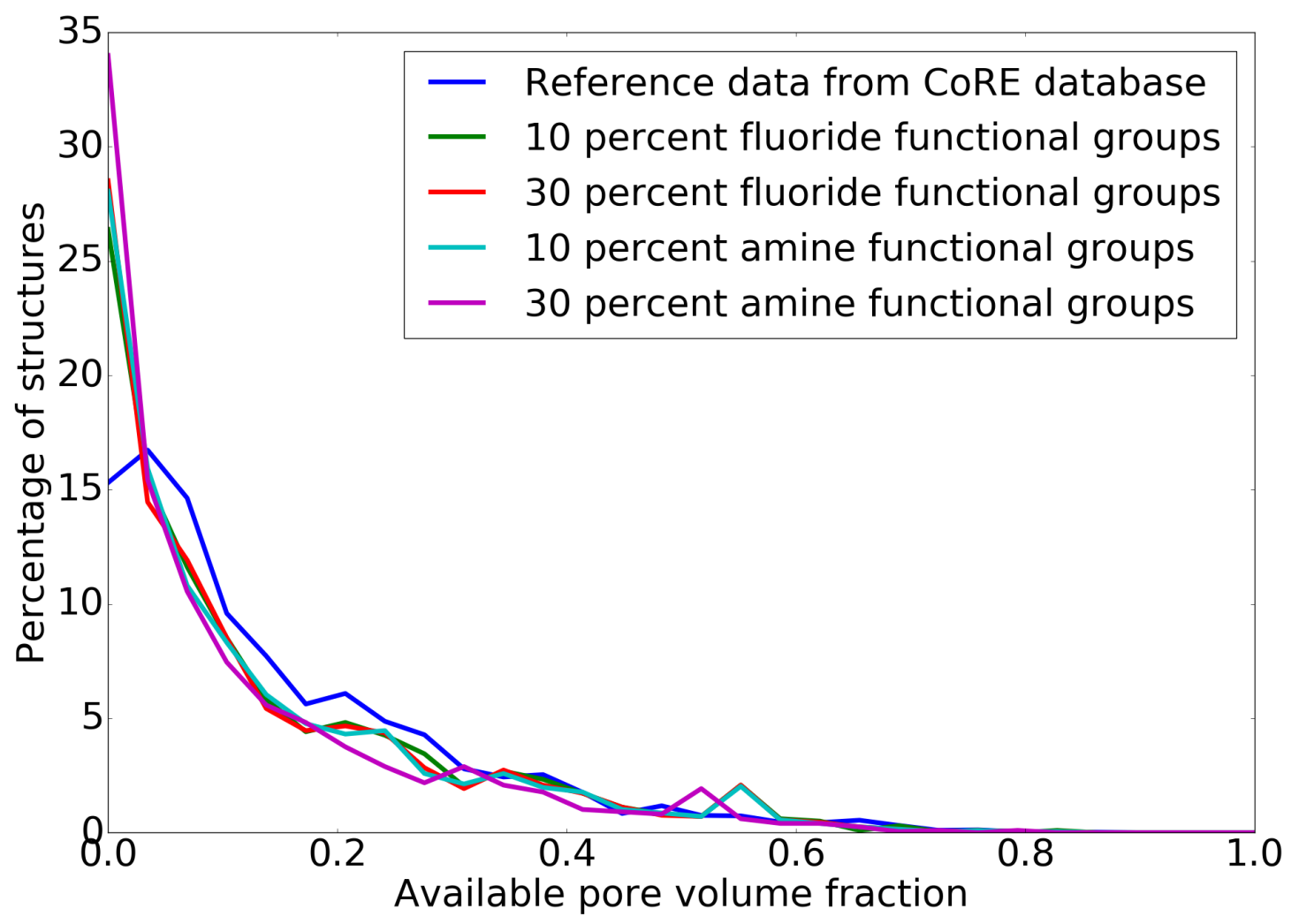

Figure 10: Available pore fraction of CoRE structures (blue) and functionalized structures. Structures were functionalized with $10 \%$ fluoride (green), $30 \%$ fluoride (red), $10 \%$ amine (aqua) or 30\% amine (purple) functional groups and re-optimized.

\section{Conclusions}

We have further extended the Universal Force Field, providing parameters corresponding to metal atom environments found in the Computation-Ready Experimental (CoRE) Database. The new parameters increase the number of CoRE structures that may be calculated with 

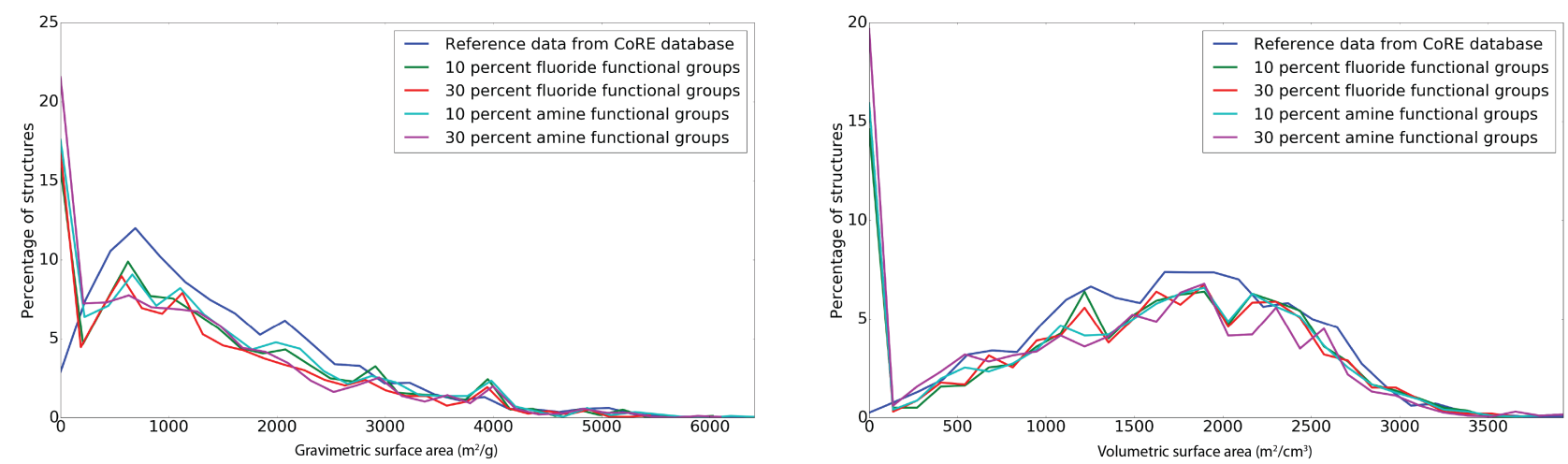

Figure 11: Gravimetric and volumetric surface area of CoRE structures (blue) and functionalized structures. Structures were functionalized with 10\% fluoride (green), 30\% fluoride (red), 10\% amine (aqua) or 30\% amine (purple) functional groups and re-optimized.

UFF to 4892, more than double the 2281 that are possible using only the original UFF parameters while maintaining similar accuracy, with $95.0 \%$ of cell parameters being within $10 \%$ of their experimental values. Where ambiguous geometries allow a metal to be described as either tetrahedral or octahedral, the availability of both parameters allows for the best fitting parameter to be employed. The new parameters may be added to any existing UFF implementation and may be used to provide high quality initial geometries of framework structures from the entire periodic table. As in the original derivation of UFF4MOF parameters, no partial charges were employed. It should be noted, though, that for the calculation of host-guest systems involving polar molecules partial charges may become necessary. In such cases, they can be added after calculation of the framework structure, e.g. using the Ionizing Charge Equilibration (I-QEq) method. ${ }^{76}$

The strength and primary utility of UFF4MOF lies in rapid structure prediction. Following a UFF4MOF calculation, the structure and consequent geometrical features are immediately available for use in screening. ${ }^{77}$ UFF4MOF naturally has the same accuracy limitations as the underlying UFF and we therefore recommend caution in employing UFF4MOF for the calculation of dynamic properties, for which it is not designed. 


\section{Acknowledgements}

This work was partially supported by the European Commission (ERC StG C3ENV GA 256962, MC-IAPP QUASINANO, GA 251149). M.A.A. acknowledges a Marie Curie Actions (MC-IIF: GA-MOF, GA 327758) fellowship. We thank ZIH Dresden for computer time.

We gratefully acknowledge Prof. Randall Snurr for providing pre-publication access to the CoRE database and the assistance of Prof. Julian Gale in incorporating UFF4MOF into the GULP software package.

Supporting Information, including all parameter derivations, list of untyped CoRE structures and analysis of metal atom environments within the CoRE database is available. This information is available free of charge via the Internet at http://pubs.acs.org 


\section{References}

(1) Li, H.; Eddaoudi, M.; O’Keeffe, M.; Yaghi, O. M. Nature 1999, 402, 276-279.

(2) Chen, Z.; Adil, K.; Weselinski, L. J.; Belmabkhout, Y.; Eddaoudi, M. J. Mater. Chem. A 2015, 3, 6276-6281.

(3) Mason, J. A.; Veenstra, M.; Long, J. R. Chem. Sci. 2014, 5, 32-51.

(4) Gutov, O. V.; Bury, W.; Gomez-Gualdron, D. A.; Krungleviciute, V.; FairenJimenez, D.; Mondloch, J. E.; Sarjeant, A. A.; Al-Juaid, S. S.; Snurr, R. Q.; Hupp, J. T.; Yildirim, T.; Farha, O. K. Chem. Eur. J. 2014, 20, 12389-12393.

(5) Nickerl, G.; Senkovska, I.; Kaskel, S. Chem. Commun. 2015, 51, 2280-2282.

(6) Li, H.-Y.; Wei, Y.-L.; Dong, X.-Y.; Zang, S.-Q.; Mak, T. C. W. Chem. Mater. 2015, 27, 1327-1331.

(7) Koukaras, E. N.; Montagnon, T.; Trikalitis, P.; Bikiaris, D.; Zdetsis, A. D.; Froudakis, G. E. J. Phys. Chem. C 2014, 118, 8885-8890.

(8) Kundu, T.; Mitra, S.; Patra, P.; Goswami, A.; Diaz Diaz, D.; Banerjee, R. Chem. Eur. J. 2014, 20, 10514-10518.

(9) Herbst, A.; Khutia, A.; Janiak, C. Inorg. Chem. 2014, 53, 7319-7333.

(10) Garcia-Garcia, P.; Muller, M.; Corma, A. Chem. Sci. 2014, 5, 2979-3007.

(11) Chung, Y. G.; Camp, J.; Haranczyk, M.; Sikora, B. J.; Bury, W.; Krungleviciute, V.; Yildirim, T.; Farha, O. K.; Sholl, D. S.; Snurr, R. Q. Chem. Mater. 2014, 26, 61856192.

(12) Allen, F. H. Acta Crystallogr., Sect. B 2002, 58, 380-388.

(13) Fang, H.; Demir, H.; Kamakoti, P.; Sholl, D. S. J. Mater. Chem. A 2014, 2, 274-291. 
(14) Yang, Q.; Liu, D.; Zhong, C.; Li, J.-R. Chem. Rev. 2013, 113, 8261-8323.

(15) Dürholt, J. P.; Galvelis, R.; Schmid, R. Dalton Trans. 2016, 45, 4370-4379.

(16) Allinger, N. L.; Yuh, Y. H.; Lii, J. H. J. Am. Chem. Soc. 1989, 111, 8551-8566.

(17) Tafipolsky, M.; Amirjalayer, S.; Schmid, R. J. Comput. Chem. 2007, 28, 1169-1176.

(18) Tafipolsky, M.; Amirjalayer, S.; Schmid, R. J. Phys. Chem. C 2010, 114, 14402-14409.

(19) Lin, L.-C.; Lee, K.; Gagliardi, L.; Neaton, J. B.; Smit, B. J. Chem. Theory Comput. 2014, 10, 1477-1488.

(20) Pham, T.; Forrest, K. A.; Hogan, A.; Tudor, B.; McLaughlin, K.; Belof, J. L.; Eckert, J.; Space, B. Cryst. Growth Des. 2015, 15, 1460-1471.

(21) Pham, T.; Forrest, K. A.; Hogan, A.; McLaughlin, K.; Belof, J. L.; Eckert, J.; Space, B. J. Mater. Chem. A 2014, 2, 2088-2100.

(22) Schierz, P.; Fritzsche, S.; Janke, W.; Hannongbua, S.; Saengsawang, O.; Chmelik, C.; Kärger, J. Microporous Mesoporous Mater. 2015, 203, 132 - 138.

(23) Grosch, J. S.; Paesani, F. J. Am. Chem. Soc. 2012, 134, 4207-4215.

(24) Vanduyfhuys, L.; Verstraelen, T.; Vandichel, M.; Waroquier, M.; Van Speybroeck, V. J. Chem. Theory Comput. 2012, 8, 3217-3231.

(25) Garcia-Perez, E.; Serra-Crespo, P.; Hamad, S.; Kapteijn, F.; Gascon, J. Phys. Chem. Chem. Phys. 2014, 16, 16060-16066.

(26) Tafipolsky, M.; Schmid, R. J. Phys. Chem. B 2009, 113, 1341-1352.

(27) Bureekaew, S.; Amirjalayer, S.; Tafipolsky, M.; Spickermann, C.; Roy, T. K.; Schmid, R. Phys. Status Solidi B 2013, 250, 1128-1141.

(28) Bristow, J. K.; Tiana, D.; Walsh, A. J. Chem. Theory Comput. 2014, 10, 4644-4652. 
(29) Vanduyfhuys, L.; Vandenbrande, S.; Verstraelen, T.; Schmid, R.; Waroquier, M.; Van Speybroeck, V. J. Comput. Chem. 2015, 36, 1015-1027.

(30) Rappe, A. K.; Casewit, C. J.; Colwell, K. S.; Goddard, W. A.; Skiff, W. M. J. Am. Chem. Soc. 1992, 114, 10024-10035.

(31) Pachfule, P.; Chen, Y.; Sahoo, S. C.; Jiang, J.; Banerjee, R. Chem. Mater. 2011, 23, $2908-2916$.

(32) Garberoglio, G.; Taioli, S. Microporous Mesoporous Mater. 2012, 163, 215 - 220.

(33) Parkes, M. V.; Demir, H.; Teich-McGoldrick, S. L.; Sholl, D. S.; Greathouse, J. A.; Allendorf, M. D. Microporous Mesoporous Mater. 2014, 194, 190 - 199.

(34) McDaniel, J. G.; Schmidt, J. R. J. Phys. Chem. A 2013, 117, 2053-2066.

(35) McDaniel, J. G.; Schmidt, J. R. J. Phys. Chem. C 2012, 116, 14031-14039.

(36) McDaniel, J. G.; Li, S.; Tylianakis, E.; Snurr, R. Q.; Schmidt, J. R. J. Phys. Chem. C 2015, 119, 3143-3152.

(37) Addicoat, M. A.; Vankova, N.; Akter, I. F.; Heine, T. J. Chem. Theory Comput. 2014, $10,880-891$.

(38) Li, H.; Eddaoudi, M.; O’Keeffe, M.; Yaghi, O. M. Nature 1999, 402, 276-279.

(39) Eddaoudi, M.; Kim, J.; Rosi, N.; Vodak, D.; Wachter, J.; O’Keeffe, M.; Yaghi, O. M. Science 2002, 295, 469-472.

(40) Chui, S. S.-Y.; Lo, S. M.-F.; Charmant, J. P.; Orpen, A. G.; Williams, I. D. Science 1999, 283, $1148-1150$.

(41) Dybtsev, D. N.; Chun, H.; Kim, K. Angew. Chem. (Int. Ed.) 2004, 43, 5033-5036. 
(42) Liu, J.; Lukose, B.; Shekhah, O.; Arslan, H. K.; Weidler, P.; Gliemann, H.; Brase, S.; Grosjean, S.; Godt, A.; Feng, X.; Mullen, K.; Magdau, I.-B.; Heine, T.; Woll, C. Sci. Rep. 2012, 2.

(43) Shekhah, O.; Wang, H.; Zacher, D.; Fischer, R. A.; Wöll, C. Angew. Chem. (Int. Ed.) 2009, 48, 5038-5041.

(44) Horcajada, P.; Serre, C.; Vallet-Regí, M.; Sebban, M.; Taulelle, F.; Férey, G. Angew. Chem. (Int. Ed.) 2006, 45, 5974-5978.

(45) Sudik, A. C.; Côté, A. P.; Yaghi, O. M. Inorg. Chem. 2005, 44, 2998-3000.

(46) Biswas, S.; Grzywa, M.; Nayek, H. P.; Dehnen, S.; Senkovska, I.; Kaskel, S.; Volkmer, D. Dalton Trans. 2009, 33, 6487-6495.

(47) Biswas, S.; Tonigold, M.; Speldrich, M.; Kögerler, P.; Weil, M.; Volkmer, D. Inorg. Chem. 2010, 49, 7424-7434.

(48) Millange, F.; Serre, C.; Ferey, G. Chem. Commun. 2002, 8, 822-823.

(49) Serre, C.; Millange, F.; Thouvenot, C.; Noguès, M.; Marsolier, G.; Louër, D.; Férey, G. J. Am. Chem. Soc. 2002, 124, 13519-13526.

(50) Loiseau, T.; Serre, C.; Huguenard, C.; Fink, G.; Taulelle, F.; Henry, M.; Bataille, T.; Férey, G. Chem. Eur. J. 2004, 10, 1373-1382.

(51) i Xamena, F. X. L.; Abad, A.; Corma, A.; Garcia, H. J. Catal. 2007, 250, $294-298$.

(52) Wang, X.; Zhao, D.; Tian, A.; Ying, J. Dalton Trans. 2014, 43, 5211-5220.

(53) Jin, J.-C.; Chang, W.-G.; Liu, J.-Q.; Xie, C.-G.; Wu, J. Inorg. Chem. Commun. 2013, $34,68-70$. 
(54) Berchel, M.; Gall, T. L.; Denis, C.; Hir, S. L.; Quentel, F.; Elleouet, C.; Montier, T.; Rueff, J.-M.; Salaun, J.-Y.; Haelters, J.-P.; Hix, G. B.; Lehn, P.; Jaffres, P.-A. New J. Chem. 2011, 35, 1000-1003.

(55) Kozachuk, O.; Yusenko, K.; Noei, H.; Wang, Y.; Walleck, S.; Glaser, T.; Fischer, R. A. Chem. Commun. 2011, 47, 8509-8511.

(56) Noei, H.; Kozachuk, O.; Amirjalayer, S.; Bureekaew, S.; Kauer, M.; Schmid, R.; Marler, B.; Muhler, M.; Fischer, R. A.; Wang, Y. J. Phys. Chem. C 2013, 117, 5658-5666.

(57) Wilmer, C. E.; Leaf, M.; Lee, C. Y.; Farha, O. K.; Hauser, B. G.; Hupp, J. T.; Snurr, R. Q. Nat. Chem. 2012, 4, 83-89.

(58) Addicoat, M. A.; Coupry, D. E.; Heine, T. J. Phys. Chem. A 2014, 118, 9607-9614.

(59) Martin, R. L.; Haranczyk, M. Cryst. Growth Des. 2014, 14, 2431-2440.

(60) Bahn, S. R.; Jacobsen, K. W. Comput. Sci. Eng. 2002, 4, 56-66.

(61) Cordero, B.; Gomez, V.; Platero-Prats, A. E.; Reves, M.; Echeverria, J.; Cremades, E.; Barragan, F.; Alvarez, S. Dalton Trans. 2008, 2832-2838.

(62) Cotton, F.; Murillo, C.; Walton, R. Multiple Bonds between Metal Atoms; Springer New York, 2006.

(63) Gale, J.; Rohl, A. Mol. Simul. 2003, 29, 291-341.

(64) Gale, J. D. Zeitschrift fur Kristallographie 2005, 220, 552-554.

(65) Jin, S.; DiSalvo, F. J. Chem. Mater. 2002, 14, 3448-3457.

(66) Salazar, J. M.; Weber, G.; Simon, J. M.; Bezverkhyy, I.; Bellat, J. P. J. Chem. Phys. 2015, 142,-.

(67) Ferey, G. Z. Anorg. Allg. Chem. 2012, 638, 1897-1909. 
(68) Kerlin, W. M.; Poineau, F.; Czerwinski, K. R.; Forster, P. M.; Sattelberger, A. P. Polyhedron 2013, 58, 115 - 119, Special Issue in Memory of Michelle Millar.

(69) Cotton, F. A.; Chakravarty, A. R.; Tocher, D. A.; Stephenson, T. A. Inorg. Chim. Acta $1984,87,115-119$.

(70) Bao, Y.; Martin, R. L.; Simon, C. M.; Haranczyk, M.; Smit, B.; Deem, M. W. J. Phys. Chem. C 2014, 119, 186-195.

(71) Gomez-Gualdron, D. A.; Gutov, O. V.; Krungleviciute, V.; Borah, B.; Mondloch, J. E.; Hupp, J. T.; Yildirim, T.; Farha, O. K.; Snurr, R. Q. Chem. Mater. 2014, 26, 56325639.

(72) Banerjee, D.; Simon, C. M.; Plonka, A. M.; Motkuri, R. K.; Liu, J.; Chen, X.; Smit, B.; Parise, J. B.; Haranczyk, M.; Thallapally, P. K. Nat Commun 2016, 7.

(73) Chen, J.; Liu, R.; Gao, H.; Chen, L.; Ye, D. J. Mater. Chem. A 2014, 2, 7205-7213.

(74) Wang, X.; Li, H.; Hou, X.-J. J. Phys. Chem. C 2012, 116, 19814-19821.

(75) Cabello, C. P.; Berlier, G.; Magnacca, G.; Rumori, P.; Palomino, G. T. CrystEngComm 2015, 17, 430-437.

(76) Wells, B. A.; De Bruin-Dickason, C.; Chaffee, A. L. J. Phys. Chem. C 2015, 119, $456-466$.

(77) Fernandez, M.; Woo, T. K.; Wilmer, C. E.; Snurr, R. Q. J. Phys. Chem. C 2013, 117, $7681-7689$. 


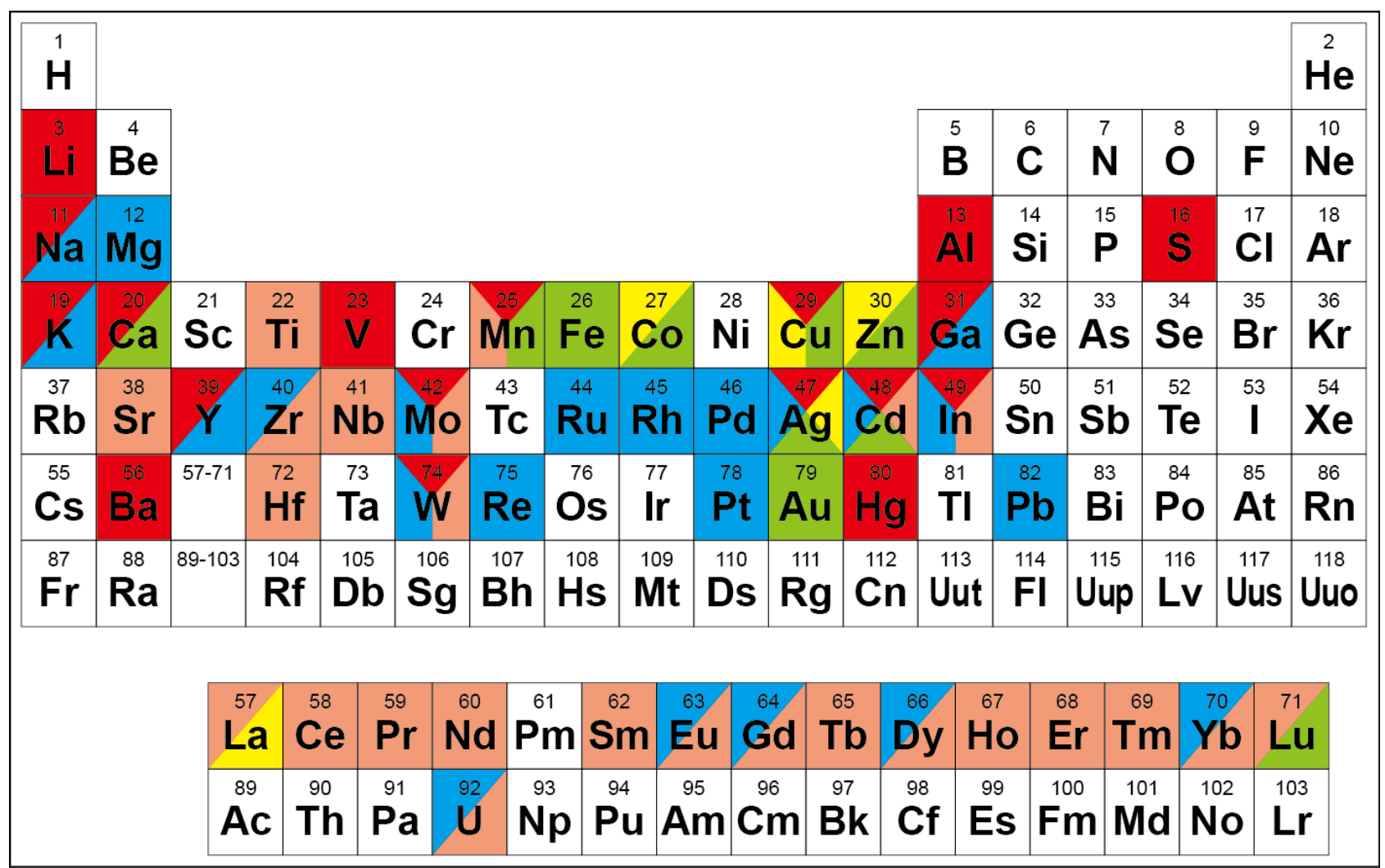

Figure 12: TOC: UFF4MOF is extended for the entire periodic table using structures from the Computation-Ready Experimental (CoRE) database. With this set of parameters, $99.6 \%$ of CoRE structures are calculable. 